\title{
Isolation and characterisation of 17 microsatellite loci for the red-billed chough (Pyrrhocorax pyrrhocorax)
}

\author{
M.A. Wenzel ${ }^{a *}$, L.M.I. Webster ${ }^{a}$, G. Segelbacher ${ }^{b}$, J.M. Reid $^{a}$ and S.B. Piertney ${ }^{a}$ \\ $20 / 04 / 11$
}

${ }^{a}$ Institute of Biological and Environmental Sciences, University of Aberdeen, Zoology Building, Tillydrone Avenue, Aberdeen AB24 2TZ, UK

${ }^{b}$ Department of Wildlife Ecology and Management, University of Freiburg, Tennenbacher Str. 4, D-79106 Freiburg, Germany

* corresponding author. email address: marius.a.wenzel.08@aberdeen.ac.uk

Word count: 96 (abstract); 99 (table captions); 831 (text without acknowledgements and references)

\begin{abstract}
We describe the isolation and characterisation of 17 microsatellite loci for the red-billed chough (Pyrrhocorax pyrrhocorax, Corvidae). Sixteen loci were polymorphic in 269 individuals from across Western Europe, with a mean allele number of $8.75 \pm 3.73 \mathrm{SD}$. Observed $\left(\mathrm{H}_{O}\right)$ and expected $\left(\mathrm{H}_{E}\right)$ heterozygosity ranged from 0.11 to 0.71 and 0.15 to 0.70 , respectively. No evidence was found for nullalleles or linkage-disequilibrium. Cross-species utility was tested on 15 Alpine choughs (Pyrrhocorax graculus) and five jackdaws (Corvus monedula). Sixteen loci amplified for Alpine chough and fifteen loci amplified for jackdaw, indicating useful application within and beyond the Pyrrhocorax genus.
\end{abstract}

The red-billed chough (Pyrrhocorax pyrrhocorax, Corvidae) is amber-listed in the UK and a Species of European Conservation Concern (Eaton et al 2009), due to a historic decline in population size and distribution range (Finney and Jardine 2003; Johnstone et al 2007). Whilst much is known about the ecology of chough populations in the UK and Europe (e.g. Blanco et al 1998; McCanch 2000; Kerbiriou and Julliard 2007; Reid et al 2003, 2008), hitherto there has been no examination of genetic population structure to inform an understanding of the extent to which individual populations are demographically independent units. We describe 17 microsatellite loci to facilitate analysis of genetic diversity within, and genetic divergence between, European chough populations. We further examine the utility of these loci for molecular studies of related taxa within the Pyrrhocorax genus.

Microsatellite loci were isolated using a magnetic bead capture enrichment approach according to Glenn and Schable (2005). Approximately $2 \mu \mathrm{g}$ of total DNA was extracted from five pooled female individuals using a DNeasy Blood and Tissue Kit (Qiagen Ltd) according to the manufacturer's instructions. The DNA was restricted with $5 \mathrm{U} R s a \mathrm{I}$ (New England Biolabs) at $37^{\circ} \mathrm{C}$ for 1 hour. Fragments were ligated to the double-stranded SuperSNX24 linker (Glenn and Schable 2005) using 1 U of T4 DNA ligase at $4{ }^{\circ} \mathrm{C}$ overnight, then hybridised to biotinylated $(\mathrm{AACT})_{8},(\mathrm{AAGT})_{8},(\mathrm{ACAT})_{8}$ and $(\mathrm{AGAT})_{8}$ oligonucleotides. The microsatellite-enriched fraction was captured with magnetic streptavidin beads (Invitrogen Ltd), then PCR-amplified using the SuperSNX24 forward oligonucleotide as a primer. PCR products were cloned using a TOPO-TA Cloning Kit (Invitrogen) according to the manufacturer's protocol. Clone insert size was checked by PCR, using standard M13 primers, and those products of between 400 and 
1000 base pairs were purified using the Qiaquick PCR purification kit (Qiagen Ltd) and sequenced using an ABI 3730 automated DNA sequencer. A total of 56 microsatellite arrays were found, of which 27 contained sufficient flanking sequences for primer design. PCR primers were designed using Primer 3 v0.4.0 (Rozen and Skaletsky 2000).

Seventeen of these pairs yielded a single PCR product of appropriate size when tested. Diversity was assessed for these loci from 269 individuals from ten sampling locations covering a broad geographic range (Scotland, Isle of Man, Northern Ireland, Ireland, Wales, England, France and Spain). Cross-species utility of the loci was tested on 15 individuals of Alpine chough (Pyrrhocorax graculus) from France and five jackdaws (Corvus monedula) from across Western Europe.

Individual PCRs were performed using the HotStarTaq Plus Mastermix Kit (Qiagen) and a G-Storm GS1 or MJ Research PTC-100 thermocycler. Reaction volumes were $10 \mu \mathrm{l}$ and contained 1X HotStarTaq Mastermix (containing $1.5 \mathrm{mM} \mathrm{MgCl}_{2}$ ), $0.8 \mu \mathrm{M}$ of each primer, $0.2 \mathrm{mM}$ of each nucleotide and 5-100 $\mathrm{ng}$ of template DNA. An initial denaturation step of $5 \mathrm{~min}$ at $95^{\circ} \mathrm{C}$ was followed by 20 TouchDown cycles from $65^{\circ} \mathrm{C}$ to $55^{\circ} \mathrm{C}$ in $0.5^{\circ} \mathrm{C}$ decrements (denaturation at $95^{\circ} \mathrm{C}$ for $30 \mathrm{~s}$, annealing for $30 \mathrm{~s}$, elongation at $72^{\circ} \mathrm{C}$ for $30 \mathrm{~s}$ ) (see Table 1 for exceptions). The programme was completed with 15 standard cycles (denaturation at $95^{\circ} \mathrm{C}$ for $30 \mathrm{~s}$, annealing at $55^{\circ} \mathrm{C}$ for $30 \mathrm{~s}$, elongation at $72^{\circ} \mathrm{C}$ for $30 \mathrm{~s}$ ) and a final elongation step at $72^{\circ} \mathrm{C}$ for 5 min. Forward primers were labelled with either 6-FAM, HEX, NED or PET fluorescent labels, and the PCR products were genotyped on an automatic ABI 3730 capillary DNA sequencer (Sequencing Service, University of Dundee, UK). Genotypes were scored by eye using the software GENEMARKER 1.4 (SoftGenetics 2010).

Sixteen out of seventeen loci were polymorphic. Allele numbers ranged from three (locus Ppy-015) to fourteen (loci Ppy-010 and Ppy-016) with a mean of $8.75 \pm 3.73 \mathrm{SD}$ (Table 1). Observed $\left(\mathrm{H}_{O}\right)$ and expected $\left(\mathrm{H}_{E}\right)$ heterozygosity were calculated using GENALEX 6.4 (Peakall and Smouse 2006) and ranged from 0.11 to 0.71 and 0.15 to 0.70 , respectively (Table 1). The software GEnEPOP 4.0.10 (Raymond and Rousset 1995; Rousset 2008) reported significant deviations from Hardy-Weinberg equilibrium $(\alpha=$ 0.05) in loci Ppy-003, Ppy-007, Ppy-008, Ppy-011, Ppy-012, Ppy-015 and Ppy-016. The presence of null alleles was examined using MICROCHECKER 2.2.3 (van Oosterhout et al 2004). Whilst there was some evidence of deviation from Hardy-Weinberg equilibrium caused by heterozygote deficiency at some loci, this was not consistent across sampling locations, suggesting its occurrence was not due to null alleles. Using GENEPOP, significant linkage disequilibrium $(\alpha=0.05)$ was detected for 53 out of 136 possible loci combinations pooled from all sampling locations $(=39 \%)$, but inconsistent occurrence of significant deviation across sampling locations suggests that the cases of deviation from linkage equilibrium are not due to physical linkage. The probability that two unrelated individuals drawn at random from the dataset will have the same genotype (probability of identity) was calculated in GIMLET 1.3.3 (Valiere 2002) and decreased from $8.241 \cdot 10^{-2}$ (most informative locus Ppy-007) to $3.100 \cdot 10^{-10}$ (all sixteen loci), indicating a high power of discrimination between individuals.

Sixteen out of the seventeen primer pairs produced scorable amplification products of equivalent size in the Alpine chough samples, and fifteen loci also amplified in the jackdaw samples (Table 2). PCR failure was increased in the tested Alpine choughs and even more so in the jackdaws, possibly due to mutations in the primer annealing sites (Jarne and Lagoda 1996; Galbusera et al 2000).

\section{Acknowledgements}

This study was funded by the Royal Society (JM Reid) and the Nuffield Foundation Undergraduate Research Bursary (MA Wenzel). We thank everyone who contributed to collecting and providing feather samples, most particularly Anne Delestrade (France), Guillermo Blanco (Spain), Christian Kerbiriou 


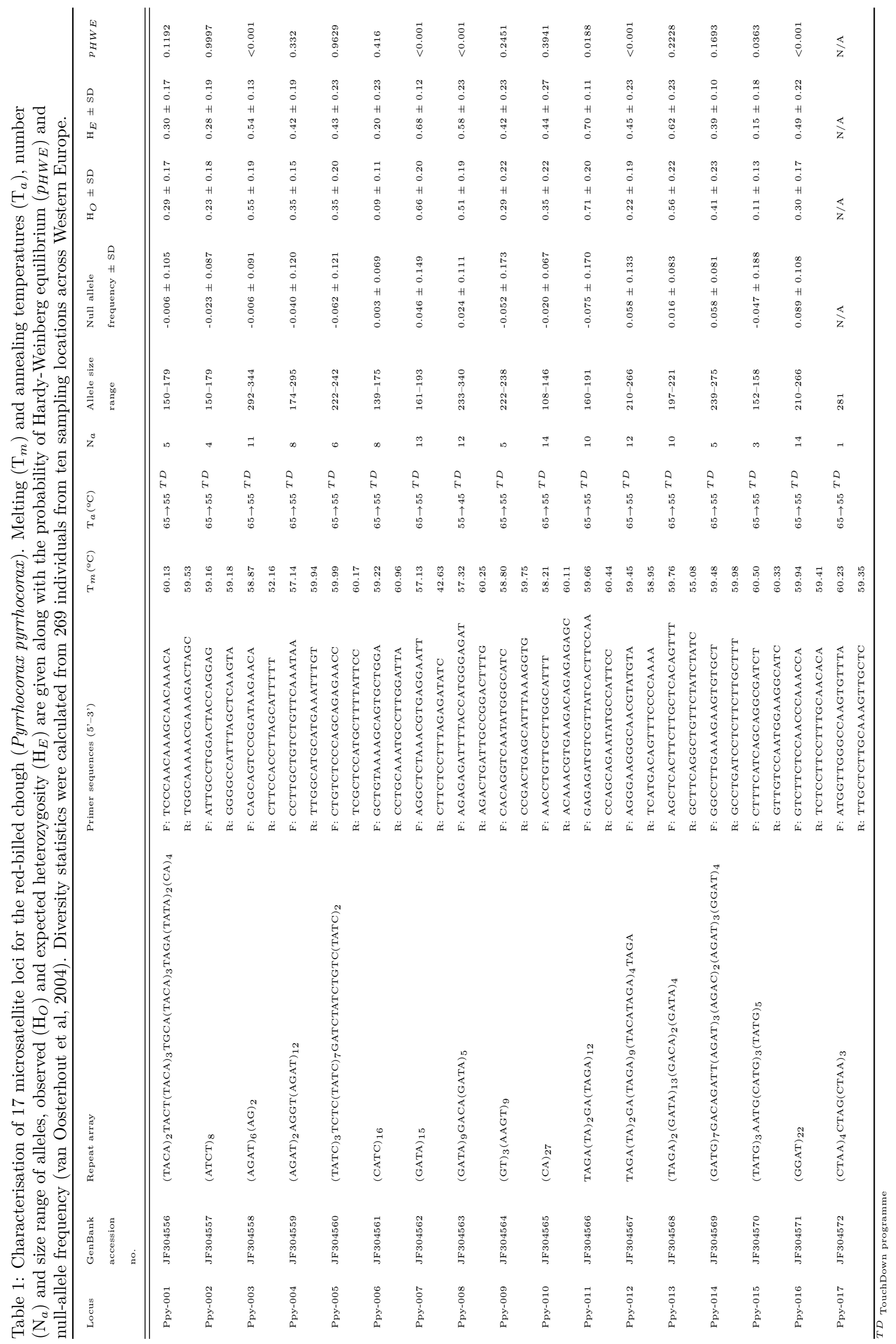


Table 2: Cross-species utility of 17 microsatellite loci developed for red-billed chough. The number of alleles at each locus are given for 269 individuals of red-billed chough (Pyrrhocorax pyrrhocorax), 15 Alpine choughs (Pyrrhocorax graculus) and 5 jackdaws (Corvus monedula).

\begin{tabular}{llll}
\hline Locus & $\mathrm{N}_{a}$ P. pyrrhocorax & $\mathrm{N}_{a}$ P. graculus & $\mathrm{N}_{a}$ C. monedula \\
\hline \hline Ppy-001 & 5 & 8 & 4 \\
Ppy-002 & 4 & 6 & 1 \\
Ppy-003 & 11 & 6 & 2 \\
Ppy-004 & 8 & 3 & 4 \\
Ppy-005 & 6 & 9 & 4 \\
Ppy-006 & 8 & 7 & 3 \\
Ppy-007 & 13 & 9 & 5 \\
Ppy-008 & 12 & 6 & 2 \\
Ppy-009 & 5 & 2 & 1 \\
Ppy-010 & 14 & - & - \\
Ppy-011 & 10 & 13 & 2 \\
Ppy-012 & 12 & 8 & 1 \\
Ppy-013 & 10 & 10 & 6 \\
Ppy-014 & 5 & 11 & 3 \\
Ppy-015 & 3 & 5 & 3 \\
Ppy-016 & 14 & 6 & - \\
Ppy-017 & 1 & 9 & 1 \\
\hline Mean \pm SD & $8.29 \pm 4.07$ & $6.94 \pm 3.29$ & $2.47 \pm 1.74$ \\
\hline
\end{tabular}

(France), Eric, Sue and Caitlin Bignal, Davy McCracken and Maria Bogdanova (Islay, Scotland), David Jardine and Mike Peacock (Colonsay, Scotland), Adrienne Stratford and Tony Cross (North Wales \& England), Mike Trewby (Ireland), Allen Moore \& Chris Sharpe (Isle of Man), and acknowledge the work of DNA Sequencing \& Services (MRCPPU, College of Life Sciences, University of Dundee, Scotland, www.dnaseq.co.uk).

\section{References}

Blanco G, Fargallo JA, Cuevas JA, Tella JL (1998) Effects of nest-site availability and distribution on density-dependent clutch size and laying date in the chough Pyrrhocorax pyrrhocorax. Ibis 140:252-256

Eaton M, Brown A, Noble D, Musgrove A, Hearn R, Aebischer N, Gibbons D, Evans A, Gregory R (2009) Birds of conservation concern 3: the population status of birds in the united kingdom, channel islands and the isle of man. British Birds 102:296-341

Finney S, Jardine D (2003) The distribution and status of the chough in scotland in 2002. Scottish Birds 24:11-17

Galbusera P, van Dongen S, Matthysen E (2000) Cross-species amplification of microsatellite primers in passerine birds. Conservat Genet 1:163-168

Glenn TC, Schable NA (2005) Isolating microsatellite dna loci. Meth Enzymol 395:202-222

Jarne P, Lagoda PJ (1996) Microsatellites, from molecules to populations and back. TREE 11(10):424429

Johnstone I, Thorpe R, Moore A, Finney S (2007) Breeding status of choughs Pyrrhocorax pyrrhocorax in the uk and isle of man in 2002. Bird Study 54:23-34

Kerbiriou C, Julliard R (2007) Demographic consequences of prey availability and diet of red-billed choughs Pyrrhocorax pyrrhocorax. Bird Study 54:296-306

McCanch N (2000) The relationship between red-billed chough Pyrrhocorax pyrrhocorax (1) breeding populations and grazing pressure on the calf of man. Bird Study 47:295-303 
van Oosterhout C, Hutchinson WF, Wills DP, Shipley P (2004) Micro-checker: software for identifying and correcting genotyping errors in microsatellite data. Mol Ecol Notes 4:535-538

Peakall R, Smouse P (2006) Genalex 6: genetic analysis in excel. population genetic software for teaching and research. Mol Ecol Notes 6:288-295

Raymond M, Rousset F (1995) Genepop (version 1.2): population genetics software for exact tests and ecumenicism. J Hered 86:248-249

Reid J, Bignal E, Bignal S, Mccracken D, Bogdanova M, Monaghan P (2008) Investigating patterns and processes of demographic variation: environmental correlates of pre-breeding survival in red-billed choughs Pyrrhocorax pyrrhocorax. J Anim Ecol 77:777-788

Reid JM, Bignal E, Bignal S, MacCracken D, Monaghan P (2003) Environmental variability, life-history covariation and cohort effects in the red-billed chough Pyrrhocorax pyrrhocorax. J Anim Ecol 72:36-46

Rousset F (2008) Genepop'007: a complete reimplementation of the genepop software for windows and linux. Mol Ecol Res 8:103-106

Rozen S, Skaletsky H (2000) Primer3 on the www for general users and for biologist programmers. Meth Mol Biol 132:365-386

SoftGenetics (2010) Genemarker v1.4 - the biologist friendly software. Online: http://www.softgenetics.com/GeneMarker.html

Valiere N (2002) Gimlet: a computer program for analysing genetic individual identification data. Mol Ecol Notes 2:377-379 